\title{
De los sustitutos de la Vulgata en el s. XVI: la Biblia de Santes Pagnino enmendada por Benito Arias Montano
}

Tras un medio centenar de ediciones antes de 1550 de la Biblia latina atribuida en buena parte a San Jerónimo como Vulgata (Vg), y aun prescindiendo de los muchos remites previos al texto hebreo en los correctoria que los Benedictinos de San Anselmo incluyeron en el aparato de su edición crítica (Roma, 1526-antes de su suspensión), aún falta mucho para conocer la historia de la Vulgata en el s. xvI, y también queda por delinear la historia de las otras versiones latinas sustitutivas de la misma Vg que Erasmo llamó el medium vas, especialmente para los años en que la sustitución no era aún objeto de animadversión como lo fue después de estallar con virulencia las controversias doctrinales. En particular hubiera querido ahondar en la actividad del Cardenal Cayetano Tommaso da Vío, quien, después de haber examinado incluso el iuxta hebraeos de Jerónimo, escribía en la introducción a su Salterio (Psalmi, 1530): «nullum apud nos textum talem qualis est in sua origine lingua scilicet hebraea»; y se valía de la ayuda de un judío y de un cristiano conocedor del hebreo para obtener un texto que le permitiese perseguir su «exposición» del Libro sagrado «secundum sensum tantummodo literalem». Cayetano quería un texto traducido, y no un texto interpretado ( «y iojalá los hubiera -exclamaba-, para toda la Biblia!»). Desgraciadamente no llegué más allá de la transcripción de algunos Salmos de dicha edición.

Entre las Biblias traducidas directamente del hebreo y del griego me detuve en la de Santes Pagnini, conocido en España más bien como Pagnino, quien fue el involuntario cireneo de un Antonio Brucioli, un Santi Marmochini, un Juan de Valdés, y lo era y lo sería aún de tantos traductores, que afirmaban traducir el AT «del hebreo» (como traducían el NT «del griego» no sin acudir como muleta 
a la versión latina de Erasmo, cuando no del mismo Pagnino) ' ${ }^{1}$. Aún en 1553, en plena época de biblicismo eclesiástico, los judíos sefarditas, al imprimir en Ferrara una Biblia traducida del hebreo, señalan el texto del dominico como tan «estimado en la Curia Romana» dando fe, de una actitud censoria que todavía no se había impuesto ${ }^{2}$.

El dominico luqués Santes Pagnino destaca entre los traductores de la Biblia de las lenguas originales en su Antiguo y Nuevo Testamento, publicados en 1528 (con varias reediciones totales y parciales), con la intención declarada de traducir del texto hebreo (del texto masorético, TM) «iuxta hebraicam vertimur veritatem»d iij ${ }^{\mathrm{V}}$, y del griego en el NT.

En los años sucesivos, la fidelidad a la hebraica veritas, de jeronimiana memoria, estaba en todas las Biblias que se ufanaban con el acceso directo al TM, que por entonces se consideraba el primitivo y el más genuino, el primum vas. De parte cristiana tal convicción respondía al renovado interés hacia el texto, y al deseo de dar más espacio a la interpretación literal. En una carta que se lee en los preliminares de la edición de Pagnino, Gian Francesco Pico della Mirandola le alaba por haber llevado la Biblia «ad umbilicum veteris testamenti».

Dejamos a los hebraístas y biblistas el examen filológico del texto y las versiones del dominico ${ }^{3}$, dejando constancia de una difusión y de una influencia que, sin embargo, no le ha merecido siquiera una mención en el vol. 3 de The Cambridge History of the Bible, titulado The West from the Reformation to the Present Day ${ }^{4}$; y empezamos por las inexactitudes y malentendidos que han afectado a algunas de sus ediciones.

En el catálogo de nuestra Biblioteca Universitaria de Padua la ficha que aquí nos ha de interesar para la edición amberiense de 1572 del AT, se atribuye a Santes Pagnino una autoría exclusiva por la lectura superficial de L. Voet, The Plantin Press. A Bibliography of Works Printed and Published by Christopher

\footnotetext{
${ }^{1}$ La utilización del Pagnini parece haber sido más servil en la Biblia de Marmochini, y ha de examinarse en cada traductor; para Valdés respecto a Erasmo véase M. Morreale, «Juan de Valdés come traduttore dei Vangeli ed il Nuovo Testamento di Erasmo», en Atti dell'Istituto Veneto de Scienze, Lettere ed Arti (Venecia 1977), 507-540, que ahora estoy enmendando y completando.

${ }^{2}$ Aludía a esto ya al principio de mi ensayo «La Biblia de Ferrara y los romanceamientos medievales: 2 Sm 22 y Ps 17(18)», en I. M. Hassán et al. (eds.), Introducción a la Biblia de Ferrara. Actas del Simposio Internacional sobre la Biblia de Ferrara (Madrid 1994), 69-139.

${ }^{3}$ Véase ahora N. Fernández Marcos y E. Fernández Tejero, «Pagnino, Servet y Arias Montano. Avatares de una traducción latina de la Biblia Hebrea», Sef 63 (2003), 283-329.

${ }^{4}$ Ed. S. L. Greenslade (Cambridge 1969). 
Plantin at Antwerp and Leiden (Amsterdam 1980), donde bajo el número 645 se lee con el encabezamiento de la ficha bajo Sante Pagnino, bible polyglot (in Hebrew, Greek, and Latin), ed. B. Arias Montano, in fol. (1572), ello como lectura superficial del título completo, a saber:

hebraicorvm bibliorvm Veteris Testamenti Latina interpretatio, opera olim Xantis Pagnini Lucensis: nunc vero Benedicti Ariae Montani Hispalensis, Francisci Raphelengii Alnetani, Guidonis, \& Nicolai Fabriciorum Boderianorum fratrum collato studio, ad Hebraicam dictionem diligentissime expensa: censorvm lovaniensivm ivdicio examinata, et academiae svffragio comprobata: 21 Christophorus Plantinus Regius Prototypographus Antuerpiae excudebat ${ }^{5}$,

que hace caso omiso del olim de la atribución al dominico (y así se lo he señalado a los bibliotecarios actuales).

No he tenido ocasión de intervenir en la magna edición titulada Bible imprimée $d u x V^{e}$ au $x V I I I^{e}$ siècle conservée à Paris, publicada por la Bibliothèque Nationale de France, en 2002, en la que se nombran como expertas a Martine Delaveau y Denise Holland. Allí, bajo el número 814, se describe el texto como de la Vulgata con la intervención de los teólogos de Lovaina: «Vulgate texte des théologiens de Louvain», donde cuadra lo de los teólogos lovanienses pero no lo que se dice de la Vulgata.

Una idea de lo mucho que queda por hacer por parte de los historiadores de la Biblia acerca del aporte de Pagnino a la historia de la interpretación del texto de la Biblia, se puede deducir leyendo el extenso trabajo bibliográfico que el P. T. M. Centi O.P. publicó bajo el título, por lo demás algo contradictorio, de «L'attività letteraria di Santi Pagnini (1470-1536) nel campo delle scienze bibliche», publicado en Archivum Fratrum Praedicatorum 5 (1945), 1-51, sin que conste si los dominicos se han ocupado ulteriormente de su correligionario Pagnini para la historia de la Biblia en latín.

Un malentendido particular afecta al comentario de la Exposición del Libro de Job de Fr. Luis de León, donde el profesor Javier San José Lera en su edición publicada en Salamanca en 1992, por lo demás excelente ${ }^{6}$, en las notas de casi

\footnotetext{
${ }^{5}$ Algo parecido es el frontispicio del Nuevo Testamento: «... quae quidem interpretatio, cum à Graecarum dictionum proprietate discedit, sensum, videlicet, magis quam verba exprimens, in margine libri est collocata: atque alia BEN. ARIAE MONTANI... opera è verbo reddita, ac diverso characterum genere distinta, etc.».

${ }^{6}$ Donde el estudio previo pormenorizado de «La exégesis bíblica en el s. XVI» me halló de acuerdo en la afirmación de que «Falta todavía un estudio moderno de conjunto de la exégesis española del s. XVI», pág. 17, quitando lo de «de conjunto».
} 
cada capítulo remite a un texto latino que atribuye sin más a Santes Pagnino como modelo del traductor, sacándolo de la magna edición amberiense de 1584, que se conserva en la Biblioteca de aquella Universidad (sign. 20347) 7 .

Múltiples son los problemas que el texto de las ediciones de Amberes presentan al lector en el libro de Job: ya la primera nota del capítulo 7, sugiere la pregunta de por qué ha de soslayarse la autoría directa de Fr. Luis de León remitiendo a una traducción latina, cuando el mismo agustino declara su dependencia del texto hebreo; e.g. ad 3:8 «No vea alborada de mañana. Lo que dize alborada de mañana, en el original o es pestañas o aquel movimiento que hazen los ojos quando se mueven aprisa», donde San José Lera remite a Santes Pagnino y también a Vatablo, quienes «traducen pálpebras» (v.i.); o ad 3:22 «et texit Deus circa eum», también atribuido por él a Pagnino, donde Fr. Luis advierte: «el original dize puntualmente: ... cubijó o atajó Dios por él».

Pero aparte de esta cuestión fundamental del acceso independiente del traductor al original, el comentario de las lecciones atribuidas a Pagnino no dan entrada al nombre de Benito Arias Montano (ya mencionado arriba en la ficha bibliográfica de la Biblioteca de Padua), porque San José Lera no identifica ni distingue oportunamente entre el texto que saca de la interlínea en la mencionada edición de Amberes y el que aparece en el margen; ambos son del dominico luqués, pero habría que advertir que el texto interlineado lo es con las intervenciones de Benito Arias Montano y de sus colegas de Amberes, distinguidas en letra cursiva; esto se deduce claramente del Prólogo de la edición, del que luego transcribiremos la parte principal.

Sin advertencia previa acertará el lector cuando, al leer ad 6:4 «Saddai [Omnipotentis] mecum» (vide p. 281 de la edición salmantina de 1609), interprete Omnipotentis, citado entre paréntesis (en otros casos entre rayas oblicuas), como de la edición de Pagnino, y Saddai como de la intervención del hebraizante Benito Arias Montano y sus colaboradores, aun cuando Fr. Luis llegara por su cuenta a esta sustitución elemental de la vuelta al TM.

En otros casos la reconstrucción requiere una interpretación más radical. Transcribimos algunas citas de los siete primeros capítulos del Libro de Job, distinguiendo en letra redonda lo que consta como de Pagnino, cuya redacción además de consignarse en el margen se entremezcla en el texto, y en cursiva las intervenciones de Arias Montano y sus colaboradores amberienses (que luego sobrentenderemos).

\footnotetext{
${ }^{7}$ En mi poder obra la edición también en folio de 1609, que para lo que aquí interesa repite el formato y el texto de la edición anterior a la que acabo de referirme. 
Valgan algunos ejemplos: ad 2:10 se lee en el comentario de San José Lera: «Pagnino traduce "secundum loqui unam fatuarum loqueris", y anota al margen: sicut loquitur una e stultis» (respecto a Vg «Quasi una de stultis mulieribus locuta es», donde la distancia no es determinante); entre líneas se lee en cursiva secundum loqui unam fatuarum por ser intervención de Arias Montano y colaboradores, siendo de Pagnino lo que consta en el margen: «sicut loquitur una e stultis».

Ad 3:8, donde San Losé Lera señala palpebras como de Pagnino (y Vatablo), la palabra es de Arias Montano (v.s.), mientras que lo que se lee en Pagnino es splendores.

Es efectivamente de Pagnino, aceptado por Arias Montano, 3:22 texit Deus; pero en 3:25 del texto que se aduce en cursiva como de Pagnino «Non tranquillus fui, neque quievi et non requievi», «tranquillus fui» es de Arias Montano, con «habui pacem» de Pagnino en el margen.

En 4:2 «Nunquid tentabimus verbum ad te lassaberis? Et cohibere in sermones quis poterit?», es de Arias Montano lo que acabamos de transcribir en cursiva, y lo que escribió Pagnino se deduce del margen como «Nonne si tentaberit quisquam loqui integre feres? Sed prohibere quis poterit» (donde en $\mathrm{Vg} 4: 2 \mathrm{~b}$ se lee: «sed conceptum sermones tenere quis poterit?»). Ad 4:6 San José Lera cita como de Pagnino lo que en realidad es de Arias Montano, además de ser inexacta la cita misma. Ad 4:21 «Profecta est dignitas eorum», Pagnino reza en el margen «translata», Arias Montano, en el interlineado, profecta. En 5:6, donde San José Lera atribuye a Pagnino «Quia non egredietur de pulvere iniquitas, et de humo [terra] non germinabit molestia», el texto del dominico reza «terra orietur perversitas» $\mathrm{y}$ el de Arias Montano «humo non germinabit molestia».

No quiero entretener más al lector con precisiones de este tipo, y con ilustraciones que requerirían un examen crítico ulterior; solo he querido evitar a otros las zozobras que a mí me apremiaron cuando tenía ya en primeras pruebas mi libro Homenaje a Fr. Luis de León, tras registrar las versiones luisianas del capítulo 7 de Job, más los salmos 41(42) y 102(103), y en columna paralela como de «Santes Pagnino» un texto que luego resultó inseguro.

De las ediciones amberienses aludidas lo que menos se ha leído es el prólogo «Benedicti Ariae Montani hispalensis in latinam ex hebraica veritate veteris testamenti interpretationem ad Christianae doctrinae studii praefacio», donde los amberienses constatan la estimación en que tenían la versión del dominico luqués, incluido su monumental Thesaurus linguae sacrae, y justifican sus intervenciones ${ }^{8}$ :

\footnotetext{
${ }^{8}$ Reproducimos el texto literalmente, excepto por la u consonántica.
} 
occasio fuit, quin maximus ille Apparatus Bibliorum de verbo e veritate Hebraica expressorum accessione cumularetur. Inter cætera vero omnia, illud huius operis a Sante Pagnino editum exemplar una omnium commendatione approbatum est. Quo quidem summorum Theologorum consilio per nos, quibus totius huius negotii procuratio et executio commissa fuerat, et approbato, et cum Louaniensi Academia communicato, ut ea de re ab ea, quid agendum esset, deliberaretur ac decerneretur, postulauimus. Itaque post maturam hac de re deliberationem, tandem ab eius Academiæ Theologis in eam sententiam itum est, ut scilicet, Regium illud opus, hac etiam in parte locupletatum prodiret. Huic autem rei optime consultum fore existimatum est, si Santis Pagnini interpretatio, veluti omnium tutissima Hebraico textui annecteretur: ita tamen, ut priusquam prælo subiiceretur, a Censoribus Theologis doctissimis, et insigni linguarum cognitione præditis, qui ad omne opus Regium recognoscendum electi sunt, prius diligenter examinaretur, ut ad iis, siquid, quod ad sententiæ puritatem pertineat, a Pagnino minus animadversum sit, annotaretur. Qui quidem, collatis inter se tribus ipsius Pagnini exemplaribus, diversis temporibus in lucem emissis, adhibito etiam eius Dictionario Hebraico, aliisque lucubrationibus et vigiliis, pleraque loca adnotarunt quæ ipse Pagninus veritatis et sapientiæ amore ductus, aliter quam in prima editione habebantur, legenda, et tenenda esse, et ingenue agnovit, et constanter asseveravit. Quamobrem nihil nos ab instituto opere alienum facturos, quin potius publicæ studiosorum utilitati consulturos, eorumque desiderio satisfacturos existimavibus, si tum ex ipsius Pagnini interpretatione, tum etiam ex Hebraicæ locutionis, hac proprietatis diligenti observatione, novo labore, novum opus contexeremus, in quo omnes dictiones quam aptissime, quo ad effici posset (neque enim omnia eodem pondere, atque eadem vi, ac proprietate, qua in primæva illa lingua leguntur, ut supra demostravimus, ex ea in aliam linguam trasferri possunt) de verbo expressæ essent id autem negotii Censores, pro ea, quam nos habere iudicarunt, linguarum cognitione (quæ quàm sit exigua, ingenue agnoscimus) nobis committendum censuerunt... Totum denique opus ita a nobis concinnatum est, ut Pagnini editione in margine, bona fide, collocata, nostram interpretationem e verbo expressam alio characteris, videlicet Italico, in eius locum subtituerunt, ut hac scilicet characterum diversitate et notulis in margine adhibitis, quid a nobis aut relictum sit, aut mutuatum perspici possit.

La Biblia latina en el s. XVI requeriría el estudio de los biblistas, que raramente se dedican a ella, siendo su preocupación la de los textos originales ${ }^{9}$; sin

\footnotetext{
${ }^{9}$ Para los antecedentes y la constitución del llamado «textus receptus» del NT griego, incluido el de la edición de Erasmo, descuella sin embargo el sucinto resumen de B. M. METZGER en la introducción de A Textual Commentary on the Greek New Testament (London-New York 1971), págs. XV-XXXI.
} 
embargo, alguna noción al respecto es necesaria, como hemos sugerido, para la edición de las traducciones vernáculas; y también para obviar a tantos juicios preconcebidos que simplifican unilateralmente los problemas de la llamada Reforma.

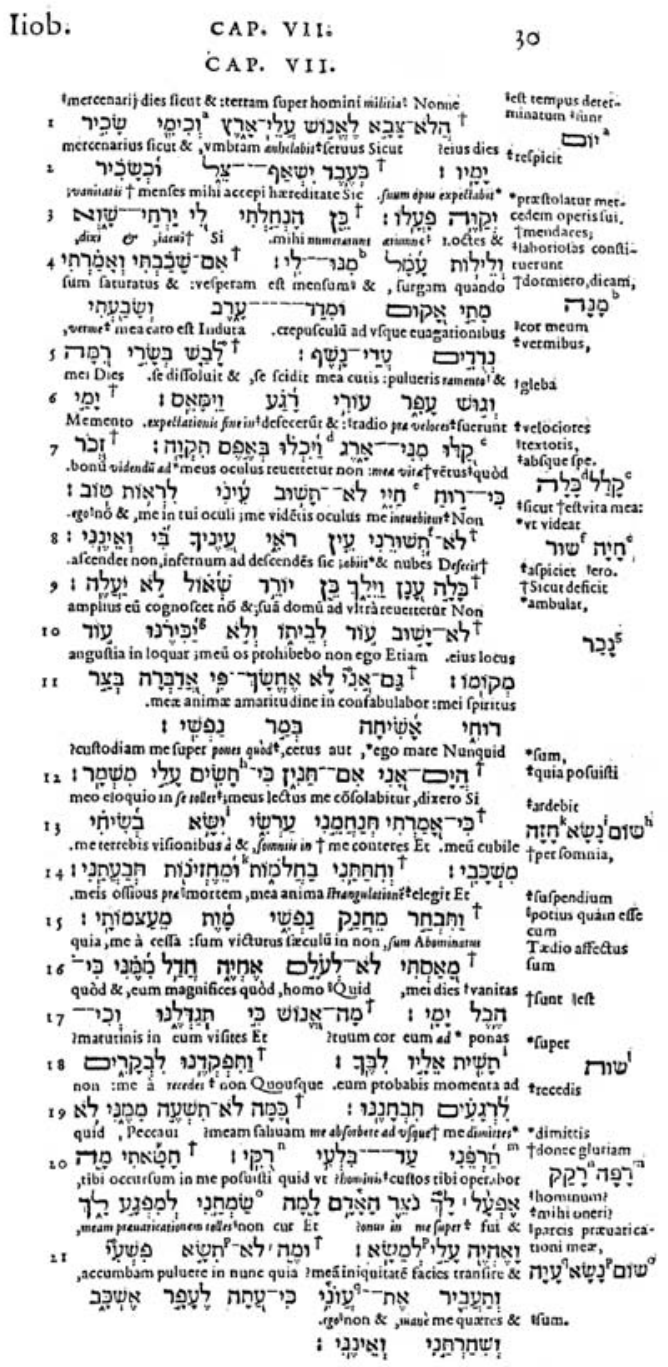

Fig. 1. Biblia de Amberes (Texto interlineal hebraico-latino, con traducción latina de Santes Pagnino y enmiendas al margen de Arias Montano). 


\section{RESUMEN}

Apuntes acerca del estudio de la Biblia durante el siglo XVI, en relación a una reciente edición de la Exposición del libro de Job de Fray Luis de León y a algunas traducciones latinas de la Biblia, en especial la de Santes Pagnino, uno de los sustitutos de la Vulgata.

Palabras Clave: Filología bíblica, Humanismo, Biblia latina, Fray Luis de León.

\section{SUMMARY}

Here are some notes on the study of the Bible in the sixteenth century regarding a recent edition of the Exposición del libro de Job by Fray Luis de León, and the Latin translations of the Bible, specially that by Santes Pagnino, one of the substitutes of the Vulgata.

KeYwords: Biblical Philology, Humanism, Latin Bible, Fray Luis de León. 